\title{
Influence of Different Media on Growth and Phycobilins in a Cyanobacterium Scytonema schmidtii, Gom.
}

\author{
Janardhan Namdeo Nehul \\ DadaPatil Rajale College, Adinathnagar Tal-Pathardi Dist-Ahmednagar- 414505(MS),India
}

\begin{abstract}
Scytonema schmidtii was isolated from the collected soil samples from different locations of Ahmednagar district of Maharashtra state(India). Identification was carried out using morphological variation and taxonomical approaches according to Desikachary. The axenic culture of Scytonema schmidtii was obtained in the laboratory. For the biomass production, different culture media were used namely BG-11, Fogg's medium, Allen and Arnon medium, Zarrouk's medium and CFTRI medium. The biomass was harvested by filtration through double layered muslin cloth and dried using air blower. After harvesting, the biomass obtained was subjected to the growth analysis. Phycobilins were estimated by following the method described by Bennett and Bogorad . Out of the different culture media used, BG-11 medium supported the growth of Scytonema schmidtii properly as compared to other media used. Phycobilins content was found to be more in Scytonema schmidtii grown in BG-11 medium followed by the Allen and Arnon medium.
\end{abstract}

Key Words: Scytonema schmidtii, Phycobilins, BG-11, Fogg's medium, Allen and Arnon medium, Zarrouk's medium and CFTRI medium.

\section{INTRODUCTION}

Cyanobacteria (blue-green algae, BGA) are morphologically diverse group of phototrophic prokaryotes, which occur in almost every habitat on earth and useful to mankind in various ways (Thajuddin and Subramanian, 2005). They constitute a vast potential resource in varied applications such as food, feed, fuel, fertilizer, medicine, industry and in combating pollution (Thajuddin and Subramanian, 2005). Until past few decades of research, cyanobacteria were of academic interests and were mostly ignored as nuisance but, now are proved as potential organisms for much biotechnological utilization (Richmond, 1990; Sundararaman and Sekar, 2001; Thajuddin and Subramanian, 2005). The interest in these organisms as generators of pharmacologically active and industrially important compounds has been stimulated by recent results (Singh et al., 2002). The carbohydrates produced by cyanobacteria have important commercial uses. Since carbohydrates are non-toxic, they are desirable and used in the food industry (Bauernfeind, 1981). Carbohydrates are frequently used in dietary additives for poultry and aquaculture farming (Hirschberg and Chamoritz, 1994).

A large number of marine nitrogen-fixing cyanobacteria have been tested for their nutritional value with the hybrid Tilapia fish fry (Mitsui et al., 1983). Thajuddin and Subramanian (2005) reported that the marine cyanobacterium Phormidium valderianum BDU 30501 has shown to serve as a complete aquaculture feed source, based on the nutritional qualities and non-toxic nature with animal model experiments. Several micro algae such as Chlorella, Scenedesmus and Coelastrum have been established as good quality protein sources (Anusuya et al., 1981). The main advantage of these species is their high protein content, therefore they are used as food supplements. They also present great benefits to human health due to their antioxidant properties, their role as activator of cell regeneration, and their positive effect on kidney and memory problems (Gutiérrez-Rebolledo, et. al 2015).

Cyanobacteria possess all the known phycobiliproteins such as phycocyanin, phycoerythrin, Phycoerythrocyanin and allo-phycocyanin. Among them, Phycocyanin and phycoerythrin are commerciality valuable. Linablue, a phycocyanin product from Dainippon Ink and chemicals Inc., Japan is an odorless, non -toxic blue powder and used for coloring candy, ice-cream, dairy products and soft drinks (Cohen, 1986). Phycoerythrin from Spirulina and other cyanobacteria is used as a food colour for products like ice-cream (Borowitzka, 1994).

Apart from the use of phycobilins as food grade dyes, they are also used as tools for basic research and medical diagnostics. They are used in fluorescence microscopy and fluorescence immunoassays (Glazer and Stryer, 1984; Kronick, 1986). Phycocyanin, the major phycobiliprotein also exhibited anti-cancer activity, stimulation of immune system and ability to treat ulcers and haemorrhoidal bleeding (Richmond, 1990). The present study was carried out for the estimation of growth and phycobilins content in Scytonema schmidtii in different culture media.

\section{MATERIALS AND METHOD}

Method of collection-The soil samples from 5-10 cm deep soil layers were collected using the scalpels. Soil samples were collected in polythene bags of size $6 \times 4$ inches. 


\section{International Advanced Research Journal in Science, Engineering and Technology}

Vol. 8, Issue 5, May 2021

DOI: $10.17148 / I A R J S E T .2021 .8578$

Nutrient media-The different culture media namely BG-11 (Rippka et al., 1979); Fogg's medium (Fogg,1949; Jacobson, 1951); Allen and Arnon's medium (Allen and Arnon, 1955); CFTRI medium (Venkataraman and Becker, 1984) and Zarrouk's medium (Zarrouk, 1966) were used for the rich growth of Scytonema schmidtii. These media were separately used in different sets.

Isolation of cyanobacterial species-The dry soil samples were spread in petri dishes and moistened with sterilized distilled water and cultures were incubated in light. When the visible growth of cyanobacteria begins to appear in the cultures, these cultures were used for the isolation of unialgal cultures of Scytonema schmidtii.

Identification of the algal samples - Morpohometric studies were carried out by using ocular and stage micrometer. The identification of Scytonema schmidtii was carried out using monograph and keys of Desikachary (1959).

Biomass production-For production of biomass, glass bottles $(300 \mathrm{~mL}$ capacity) were used. The bottles were filled with $100 \mathrm{~mL}$ medium and autoclaved. The inoculum was ground in the sterile mortar and pestle in laminar air flow. Then the bottles were inoculated with $5 \mathrm{~mL}$ of unialgal suspension of Scytonema schmidtii and labeled properly. All the cultures were maintained in the culture room at temperature $28 \pm 2^{\circ} \mathrm{C}$ under $8-\mathrm{h}$ light/16-h dark photoperiod with a photosynthetic photon flux density of $40 \mu$ moles $^{-2} \mathrm{~S}^{-1}$ provided by cool white fluorescent tube lights .After harvesting, the biomass obtained was subjected to the growth and proteins analysis.

\section{ESTIMATION OF PHYCOBILINS}

Phycobilins were estimated by following the method described by Bennett and Bogorad (1973). Two mL cell suspension was centrifuged at $4500 \mathrm{rpm}$ for 10 minutes and pellet of algal biomass was used for the estimation of total phycobilins. The pellet of biomass of Scytonema schmidtii was blotted with filter papers to remove maximum quantity of water from it. The pellet thus dried was homogenized in $100 \mu 1$ glycerol and placed in the dark for 3 hours. After the contents were mixed, $5 \mathrm{~mL}$ of $10 \%$ ammonium sulphate containing $1 \mathrm{~mL}$ of $3 \mathrm{mM}$ sodium azide and $1 \mathrm{~mL}$ of $10 \mathrm{mM} \mathrm{Na} 2 \mathrm{EDTA}$ (Whyman,1992). The resultant cell suspension was sonicated for 10 minutes and then centrifuged at $4500 \mathrm{rpm}$ for 10 minutes. Absorbance of the supernatant solution was determined at $665 \mathrm{~nm}, 620 \mathrm{~nm}$ and $650 \mathrm{~nm}$ on UV Visible spectrophotometer (Systronics, India; model 2202). The amounts of phycoerythrin, phycocyanin and allophycocyanin were calculated by using following equations (Bennett and Bogorad, 1973).

\section{A. Amount of Phycoerythrin (PE)}

$=\mathrm{A}_{565^{-2}} 2.8[\mathrm{PC}]^{-1} .34[\mathrm{APC}] \mathrm{mg} \mathrm{ml}^{-1} / 12.7$

B. Amount of Phycocyanin (PC), $=\mathrm{A}_{620^{-}} 0.7 \times \mathrm{A}_{650} \mathrm{mg} \mathrm{ml}^{-1} / 7.38$

\section{Amount of allophycocyanin (APC)}

$=\mathbf{A}_{650} 0.19 \times \mathbf{A}_{620} \mathrm{mg} \mathrm{ml}^{-1} / 5.65$

Where, $\mathrm{A}_{565}=$ Absorbance of supernatant solution at 565nm,

$\mathrm{A}_{620}=$ Absorbance of supernatant solution at $620 \mathrm{~nm}$,

$\mathrm{A}_{650}=$ Absorbance of supernatant solution at $650 \mathrm{~nm}$.

D. Sum of PE, PC and APC gives content of total phycobiliprotiens.

Amount of Phycobiliprotiens are expressed as \% of dry weight basis.

\section{RESULTS AND DISCUSSION}

Out of the different culture media used, BG-11 medium supported the growth of Scytonema schmidtii properly as compared to other media used. Allen and Arnon medium also supported growth but after 20 to 25 days, photo bleaching of biomass was observed. Other growth media, such as Fogg's medium and Zarrouk's medium supported the growth of Scytonema schmidtii but the growth rate was very slow.

Yield of biomass is one of the direct measures of quantity of biomass produced per unit area within a specific time. Higher yield indicates higher biomass produced per unit area. Comparison of Scytonema schmidtii in different media showed that highest biomass per bottle in terms of dry weight was produced in BG-11 medium followed by Allen and Arnon medium. The phycobilins content was found to be more in the Scytonema schmidtii grown in BG-11 medium followed by the Allen and Arnon medium. CFTRI and Zarrouk's medium showed poor response for the phycobilins content as compared to other media.

Influence of different media on growth and phycobilins in Scytonema schmidtii

\begin{tabular}{|c|l|c|c|c|}
\hline Sr.no & Medium & Fresh wt. $(\mathrm{g})$ & Dry wt. $(\mathrm{g})$ & Phycobilins \% \\
\hline 1 & BG-11 & $1.89 \pm 0.12^{\mathrm{a}}$ & $0.17 \pm 0.05^{\mathrm{a}}$ & $6.58 \pm 0.82^{\mathrm{a}}$ \\
\hline 2 & Allen \& Amon & $1.60 \pm 0.10^{\mathrm{b}}$ & $0.16 \pm 0.04^{\mathrm{a}}$ & $5.46 \pm 0.75^{\mathrm{b}}$ \\
\hline
\end{tabular}




\section{International Advanced Research Journal in Science, Engineering and Technology}

Vol. 8, Issue 5, May 2021

DOI: $10.17148 /$ IARJSET.2021.8578

\begin{tabular}{|c|c|c|c|c|}
\hline 3 & Fogg's Medium & $1.21 \pm 0.09^{\mathrm{c}}$ & $0.10 \pm 0.03^{\mathrm{b}}$ & $5.23 \pm 0.57^{\mathrm{b}}$ \\
\hline 4 & Zarrouk' Medium & $1.38 \pm 0.15^{\mathrm{c}}$ & $0.14 \pm 0.05^{\mathrm{a}}$ & $4.49 \pm 0.62^{\mathrm{c}}$ \\
\hline 5 & CFTRI & $1.52 \pm 0.22^{\mathrm{b}}$ & $0.15 \pm 0.07^{\mathrm{a}}$ & $4.09 \pm 0.95^{\mathrm{c}}$ \\
\hline
\end{tabular}

Values are mean $\pm \mathrm{SE}$ of three independent experiments.

Cyanobacteria are photoautotrophic bacteria and require all the essential major and minor elements. The heterocystous cyanobacteria fix atmospheric nitrogen and they can use atmospheric nitrogen as a source of nitrogen. In bottles, the medium does not come in contact with atmospheric nitrogen and the source needs to be added in the culture medium. If the culture medium is devoid of nitrogen, it results in poor growth of cyanobacteria. Similar results were reported by Olatz (1991); medium lacking nitrogen source, results in yellowish green color of the cells which is a characteristic of nitrogen deficiency. In the culture methods like photo- bioreactors, pure nitrogen is continuously bubbled into culture medium, (Humberto et al., 1989; Vonshak, 1993; Roxana et al., 2000) so that cultures do not get affected due to nitrogen deficiency.

The growth of Scytonema schmidtii was more in BG-11 medium than in other media. For optimum growth of cyanobacteria, appropriate $\mathrm{Ka}^{+}: \mathrm{Na}^{+}$ratio is required in the cytoplasm. Adequate $\mathrm{Na}^{+}$is required by nitrogen fixing cyanobacteria for conversion of molecular nitrogen into ammonia (Becker, 1994). BG-11 medium consists moderate concentration of $\mathrm{Na}^{+}$and in Allen and Arnon medium, Zarrouk's medium and CFTRI medium there is high concentration of $\mathrm{Na}^{+}$while in Fogg's medium; there is no $\mathrm{Na}^{+}$source. Scytonema schmidtii is from moist soil habitat, which may not require high concentration of $\mathrm{Na}^{+}$ions in the medium.

\section{Phycoerythrin}

\section{INFLUENCE OF CULTURE MEDIA ON PHYCOBILINS}

The percentage of phycoerythrin was affected by the composition culture media. In all the media used, phycoerythrin was found to be highest in the Fogg's medium in Scytonema schmidtii. The highest amount of phycoerythrin $1.43 \%$ was produced in Scytonema schmidtii cultured in BG-11 medium. CFTRI medium supported poorly for the production of phycoerythrin as compared to other media used.

\section{Phycocyanin}

The amount of phycocyanin varied from medium to medium. BG-11 and Fogg's medium were the best media for the accumulation of the phycocyanin content in Scytonema schmidtii species. The highest phycocyanin content was found in Scytonema schmidtii cultured in BG-11medium and lowest $1.22 \%$ in Scytonema schmidtii grown in CFTRI medium. The quantity of phycocyanin produced in BG-11 was found in between the range of 3.97-1.22\%. In Fogg's medium the percentage was in the range of 3.67-1.72\%. There was a production of average amount of phycocyanin in other culture media.

\section{Allophycocyanin}

In Scytonema schmidtii, maximum allophycocyanin content was found in the Fogg's medium followed by the BG-11 medium. Other media showed poor response for the allophycocyanin content in Scytonema schmidtii. The maximum quantity $2.78 \%$ was occurred in Scytonema schmidtii grown in BG-11 and 2.19\% cultured in Fogg's medium. There was an accumulation of less amount of allophycocyanin in Scytonema schmidtii species grown in CFTRI medium.

BG-11 medium was superior for the total phycobilin content in Scytonema schmidtii species studied followed by the Fogg's medium. CFTRI medium shows very poor response for the total phycobilins content in Scytonema schmidtii species studied. Composition and $\mathrm{pH}$ of the medium also affect the content of phycobiliprotein and there is change in the colour of culture of cyanobacteria. The production of phycobilins is greatly affected by the $\mathrm{pH}$. This indicates the inability of the cyanobacteria to maintain a constant internal pH (Roe, 2000).

\section{CONCLUSION}

There is an effect of different culture media on growth. It may be because of either composition of culture medium or $\mathrm{pH}$ value. The percentage of phycobilins also changed in various culture media used.

\section{REFERENCES}

Allen MB, Arnon DI (1955) Studies on nitrogen fixing blue green algae. I. Growth and nitrogen fixation in Anabaena cylindrica. Plant Physiol. 30:366372

Anusuya. DM, Subbulaxmi G, Madhavi DM, Venkataraman LV (1981) 'Studies on the proteins of mass cultivated blue green alga (Spirulina platensis). J. Agric. Food Chem. 29:522-525

Bauernfeind JC (1981) Carotenoids as colorants and Vitamins A Precursors. London: Academic Press

Bennett A, Bogorad L (1973) complementary chromatic adaptationin a filamentous blue-green alga. The Journal of Cell Biology 58: 419-435

Borowitzka MA (1994) In: Proceedings of the first Asia-Pacific Conference on Algal Biotechnology. (Eds.) Phang SM, Lee YK, Borowitzka MA and Whitton BA, University of Malaya, Kuala Lumpur, pp. 5-15

Cohen Z (1986) 'Products from microalgae'. In handbook of microalgal Mass Culture. (Eds.). Richmond, A. Boca Raton FL, USA: CRC Press, pp. 421-454

Desikachary TV (1959) A monograph on Cyanophyta, ICAR Publication, New Delhi.1-686 


\section{International Advanced Research Journal in Science, Engineering and Technology}

Vol. 8, Issue 5, May 2021

\section{DOI: $10.17148 /$ IARJSET.2021.8578}

Fogg GE (1949) Growth and heterocyst production in Anabaena cylindrica Lemm. II. In relation to carbon and nitrogen metabolism. Ann. Bot. 13: 241-259

Glazer AN, Stryer L (1984) Phycofluor probes. Trends Biochem. Sci. 9:423-427.

Gutiérrez-Rebolledo, G.A.; Galar-Martínez, M.; García-Rodríguez, R.V.; Chamorro-Cevallos, G.A.; Hernández-Reyes, A.G.; Martínez-Galero, E.(2015) Antioxidant effect of Spirulina (Arthrospira) maxima on chronic inflammation induced by Freund's complete adjuvant in rats. J. Med. Food, 18, 865-871.

Hirschberg J, Chamoritz D (1994) In: The Molecular Biology of Cyanobacteria, (Ed.). Bryant, DA Dordrecht, The Netherlands: Kluwer Academic Publishers.pp.559-579

Humberto J, Silva IC, Rodolfo JE (1989). Effect of nutritional factors on the culture of Nostoc sp.as a source of phycobiliprotiens. Appl Microbiol Biotechnol 31: 293-297

Jacobson L (1951) Maintenance of iron supply in nutrient solutions by a single addition of ferric potassium ethylene diamine tetra-acetate. Plant Physiology 26: 411-413

Kronick MN (1986) The use of phycobiliproteins as fluorescent labels in immunoassay. J Immunol Methods 92:1-13

Mitsui A, Enternmann B, Gill K (1983) Indoor and outdoor cultivation of Tilapia in seawater with algae as a sole food source. InProceedings of the 2nd North Pacific Aquaculture System, Tokyo University, Japan, pp. 323-340

Olatz F, Ramon G, Juan LS (1991) Carotenoides composition in the Cyanobacterium Phormidium laminosum. Effect of nitrogen starvation. FEBS Letters, 282: 300-304

Richmond A (1990) In: Algal Biotechnology, (Eds.). Round FE, Chapman DJ, Bristol UK: Biopress Ltd. pp. 269-330

Rippka R, Deruelles J, Waterbury JB, Herd man M, Stainer RY (1979) Generic assignments. Strain histories and properties of pure cultures of cyanobacteria. J. Gen. Microbiol. 111: 1-61

Roe,S.(2000). Protein Purification Techniques: A practical Approach.Oxford University press, Oxford,UK.

Roxana Olvera-Ramirez, Marisela Coria-Cedillo, Rosa Olivia Canizares-Villanuevea Fernando Martinez-Jeronimo, Teresa Ponce-Noyola, Elivira Rios-Leal,(2000). Growth evaluation and byproduct characterization of Calothrix sp. Bioresource Technology 72: 121-124

Singh DP, Tyagi MB, Kumar A, Prasuna EG (2002) Bioactive Secondary Metabolites from cyanobacteria. Pg.275-292. In Algological research in India. Edt. N. Anand, Pbl. Bsmps Dehradun. India

Sundararaman M, Sekar S (2001) Biotechnological potential of cyanobacteria. In: Algal biotechnology, Trivedi PC (ed.), Pointer Publishers, Jaipur, India. pp 31-52

Thajuddin N, Subramanian G (2005) Cyanobacterial biodiversity and potential applications in biotechnology, Curr. Sci. 89: 47-57

Venkatarama, LV, Becker EW (1984) Production and utilization of the blue-green alga Spirulina in India. Biomass 4: $105-125$

Vonshak A (1993) Spirulina platensis (Arthrospira): Physiology, Cell Biology and Biotechnology. Taylor \&Francis, London. ISBN 0-7484-0674-3

Whyman M (1992) An in vitro method for estimation of phycoerythrin concentration in marine cyanobacteria (Synecoccus Sp.), Limol. Oceanogr 37: 1300-1306

Zarrouk C (1966) Contribution a l'etude d'une cyanophycee. Influence de divers' facteurs physiques et chimiques sur la croissance et la photosyntheses de Spirulina maxima.Ph.D.Thesis. University of Paris, France 